\title{
What do most erectile dysfunction guidelines have in common? No evidence-based discussion or recommendation of heart-healthy lifestyle changes and/or Panax ginseng
}

\author{
Mark A Moyad ${ }^{1}$ and Kwangsung Park ${ }^{2}$
}

Sexual health or erectile dysfunction (ED) state of the art guidelines provide a thorough overview of conventional prescription or other notable extrinsic treatment options. Yet, over the past 10-15 years, a plethora of international researchers have established that individual and comprehensive lifestyle changes can prevent and potentially improve ED. We review the lifestyle evidence that should equate to grade A or level 1 evidence recommendations for ED. We also review the evidence for Panax ginseng, an over-the-counter (OTC) dietary supplement with a 35-year history of laboratory investigations, multiple positive randomized trials over approximately 15 years and several independent meta-analyses and systematic reviews. Perhaps it is time to at least discuss and even emphasize lifestyle and other non-conventional interventions in ED guidelines so that patients can explore a diversity of potentially synergistic choices with their physicians and can improve their quality and quantity of life. Ignoring the consistent, positive data on lifestyle modifications in ED guidelines, for example, is tantamount to ignoring diet and lifestyle changes to reduce the risk of or ameliorate cardiovascular diseases. Asian Journal of Andrology (2012) 14, 830-841; doi:10.1038/aja.2012.82; published online 24 September 2012

Keywords: diet; erectile dysfunction; lifestyle; Panax ginseng; sexual health

\section{INTRODUCTION}

It appears that patients construe that when a prescription of diet and exercise is not effective, one can turn to cholesterol-lowering over-thecounter (OTC) and prescription medications. This accepted mantra in cardiovascular medicine seems true today for multiple aspects of preventive health. For example, if lifestyle changes and calcium and vitamin $\mathrm{D}$ are not able to reduce the risk of bone loss, then most clinicians would arguably recommend a bone mineral density prescription medication. Interestingly, conventional medical recommendations evolved over a decade ago to adopt this type of lifestyle-first philosophy, as evidenced by guidelines from a plethora of specialty groups. ${ }^{1,2}$ However, one area of medicine that appears to be missing, or at least not emphasizing lifestyle and OTC recommendations despite ample data, is male and female sexual dysfunction, especially erectile dysfunction (ED). It is our opinion that the omission of these recommendations from urologic guidelines should be reevaluated based on the current quantity and quality of the data, and the overall health improvements these lifestyle recommendations and OTC options could immediately provide for patients.

An exception to the omission of lifestyle recommendations in urology should be lauded, such as the recent European Association of Urology guidelines that state 'lifestyle changes and risk factor modification must precede or accompany ED treatment', and classify the level of evidence as ' $1 b$ ' with a grade of ' $A$ ', which essentially is tantamount to almost any other conventional treatment available in sexual medicine. ${ }^{3}$ However, despite all other medical treatments being thoroughly discussed in the European guidelines, lifestyle changes and OTC options received no further mention or discussion beyond just the actual recommendation. Clinicians need to be able to cite specific studies and elaborate on general and specific lifestyle recommendations to improve their credibility with patients and to improve compliance and enthusiasm for these changes.

\section{WEIGHT LOSS VIA DIET OR CALORIC REDUCTION AS A FIRST- LINE PREVENTION AND TREATMENT OPTION}

Perhaps one of the most critical evidence-based recommendations that should be discussed with patients is the maintenance of a healthy weight, or reductions in weight or waist size, to reduce morbidity and mortality and to improve overall and sexual health. One of the largest prospective studies ever conducted was the European Prospective Investigation into Cancer and Nutrition, which included a total of 359387 participants, aged 25-70 years, from nine countries. ${ }^{4}$ The mean follow-up in that study was 9.7 years, and a total of 14723 participants died during this time period. The lowest risk of death was associated with a body mass index (BMI; in $\mathrm{kg} \mathrm{m}^{-2}$ ) of approximately 24-25 for men and women. However, after adjustment for BMI, larger 
waist circumference (WC) measurements were also strongly correlated with all-cause and disease-specific mortality, but both BMI and WC measurements provided better correlation than did one or the other measurement alone. Both measurements offer synergistic value for the patient attempting to lose weight. ${ }^{5} \mathrm{WC}$ of over $100 \mathrm{~cm}$ is concerning and is associated with metabolic syndrome, but a WC of less than $86 \mathrm{~cm}$ carried the lowest risk of all-cause mortality in the European Prospective Investigation into Cancer and Nutrition study. ${ }^{4}$ Interestingly, this same study demonstrated a significant increase in advanced prostate cancer with greater abdominal obesity. ${ }^{6}$ Table 1 summarizes the basic interpretation of the BMI and WC ranges of values. $^{5}$

The majority of men reporting ED symptoms (up to 80\%) are overweight or obese, and men who carry abnormal amounts of weight have a consistently higher risk of sexual dysfunction than do men with a normal BMI, especially with aging. ${ }^{7-11}$ Thus, it is no longer difficult to conclude that obesity is a risk factor for sexual dysfunction and that cardiovascular disease risk factors are predictive of future erectile function and vice versa. ${ }^{11-13}$ In the placebo arm of the Prostate Cancer Prevention Trial, men with incident or prevalent ED had a significant $(P<0.001) 45 \%$ increased risk of a subsequent cardiovascular event during the study follow-up. ${ }^{13}$ This risk was noted to be similar to the risk of a current smoker or that of a man with a family history of myocardial infarction. It is also interesting that the average man in the Prostate Cancer Prevention Trial study was overweight (BMI 27.5) and that increases in BMI were significantly associated with ED during the clinical trial and a subsequent cardiovascular event in the final multivariate analysis.

What is the potential value of weight loss in men in terms of sexual function? In one of the largest meta-analyses ( $n=6800$ men, 31 studies) of hormonal changes and obesity, researchers found that 18 of 20 studies measuring testosterone, 15 of 16 measuring sex hormone-binding globulin and 10 of 12 investigating free testosterone, found an inverse correlation between BMI and these parameters. ${ }^{14} \mathrm{~A}$ total of $4-10$ studies found a direct relationship between BMI and estradiol. The conclusion of this unique meta-analysis was unequivocal: 'There was strong evidence of a negative relationship for testosterone, sex hormone-binding globulin and free testosterone with increased BMI'. Recent studies continue to find significant inverse relationships between weight and testosterone and increases in estradiol. ${ }^{15,16}$ Mechanisms proffered in these recent manuscripts to construe the inverse correlation between weight

Table 1 BMI and WC values for men and women ${ }^{\mathrm{a}}$

\begin{tabular}{ll}
\hline$B M I$ value & Interpretation \\
\hline$<25$ & Normal \\
$25-29$ & Overweight \\
$>30$ & Obese \\
\hline$W C$ value in men & Interpretation \\
\hline$<89 \mathrm{~cm}$ & Normal \\
$89-100 \mathrm{~cm}$ & Overweight \\
$>101 \mathrm{~cm}$ & Obese \\
\hline$W C$ value in women & Interpretation \\
\hline$<83 \mathrm{~cm}$ & Normal \\
$83-92 \mathrm{~cm}$ & Overweight \\
$>94 \mathrm{~cm}$ & Obese \\
\hline
\end{tabular}

Abbreviations: BMI, body mass index; WC, waist circumference.

${ }^{\text {a }}$ Some research methods also use a waist-to-hip ratio, for which lower values

(smaller waist and larger hip) indicate lower risk of future disease outcomes. and testosterone include: suppression of gonadotropin-releasing hormone and luteinizing hormone/follicle-stimulating hormone pulse, Leydig cell inhibition, increased aromatase activity in adipose tissue, higher estrogen activity inhibiting enzymatic activity required for intratesticular steroidogenesis, excessive insulin concentrations impacting steroid signaling and protein carrier production, and enhanced peripheral androgen metabolism with a simultaneous reduction in overall testosterone levels. ${ }^{15,16}$

Additionally, a potential reduction in pregnancy rates with higher BMI is plausible because of sexual dysfunction, higher scrotal temperatures and adipose hormones. ${ }^{17}$

A change in existing urology guidelines requires more than a consistent correlative observation, but even partial amelioration or prevention through lifestyle changes should strengthen the case. Weightloss studies of both short- and long-term duration that do not include a rigid exercise component (only caloric modification or restriction) are demonstrating improvements in testosterone and sexual function. For example, a pilot study of 43 obese men followed for just 14 weeks on a weight-loss program found significant $(P=0.02)$, graded increases in total testosterone with greater weight loss. ${ }^{18}$ Median baseline testosterone was in the range of approximately $7-9 \mathrm{nmoll}^{-1}$, and a higher BMI was associated with a lower initial value. Men losing 3.5\%$12.1 \%, 12.2 \%-17.1 \%$ and $17.2 \%-25.4 \%$ of their body weight experienced adjusted mean increases in testosterone levels of $0.7,3.3$ and $3.7 \mathrm{nmol}^{-1}$, respectively. The free androgen index also increased significantly in the group with the largest weight reduction. Total sperm count, semen volume and anti-Müllerian hormone significantly increased.

Rapid weight loss also appears to be an effective method for improving lower urinary tract symptoms (LUTSs), libido and/or ED in a short period of time. ${ }^{19}$ An 8-week low-calorie diet (approximately $900 \mathrm{cal}$ ories day ${ }^{-1}$ ) was given to non-diabetic and diabetic men with a BMI $>30$ and a WC $>102.1 \mathrm{~cm}$ compared with a control group. A total of 68 men completed the study, and the mean age of the participants was 49.7 years. This was a nonrandomized intervention study and a dietitian communicated with the participants and monitored their progress throughout the study period. Weight loss of approximately $10 \%$ or more was associated with significant improvements in insulin sensitivity, testosterone, erectile function and sexual desire, as well with reductions in WC and LUTS, in both diabetic and non-diabetic men. Improvement in LUTS was associated with a significant increase in erectile function, sexual desire and testosterone. Similar improvements were noted in non-diabetic and diabetic individuals on the sexual function score of the International Index of Erectile Function (IIEF-5) but not in the International Prostate Symptom Score (-6.4 vs. -2.1). In the non-diabetic men, the mean weight and waist losses in 8 weeks were over $12 \mathrm{~kg}$ and approximately $12.5 \mathrm{~cm}$, respectively. This simply means that such dramatic weight loss is plausible with severe caloric restriction without any initial change in physical activity levels. Furthermore, any decrease in LUTS with weight loss could be another mechanism of action that improves erectile function, similar to what is touted in conventional medicine with pharmacological agents. ${ }^{20}$

Another study of weight loss that combined short-term and longterm data and different caloric modification or diet options continues to support the notion that weight loss can be achieved with multiple programs and more practical cost-effective changes. ${ }^{21}$ For example, an 8 -week study of 31 obese (mean BMI of 35 and WC of $122 \mathrm{~cm}$ ) men with type 2 diabetes (mean age 60 years) who received a 1000 -calorie day $^{-1}$ meal replacement low-calorie diet $(n=19)$ or a high-protein (HP), low-fat, reduced-carbohydrate $(n=12)$ diet that cut total daily 


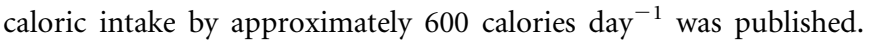
After 8 weeks, all subjects were then placed on the HP (600 calorie $\mathrm{day}^{-1}$ reduction) diet for another 44 weeks. After 8 weeks, the total weight and waist size of men in the low-calorie diet group was reduced by $10 \%$ compared with $5 \%$ for men in the HP diet group. Both diets caused significant improvement in glucose, LDL, sex hormone-binding globulin, IIEF-5, Sexual Desire Inventory (SDI), International Prostate Symptom Score and endothelial function as measured by brachial artery flow-mediated dilatation and reduced soluble E-selectin. ED, sexual desire and urinary symptoms improved by a similar degree with both diets. C-reactive protein and IL-6 were reduced with the HP diet. At 52 weeks, the metabolic benefits were maintained and sexual and urinary parameters continued to improve. Men switching to a more moderate diet after an 8-week caloric restriction challenge showed that results and compliance were sustainable up to 1 year. Mean weight loss after 1 year was approximately $9 \mathrm{~kg}$, and mean reductions in the International Prostate Symptom Score from 9 to 4 occurred after 52 weeks. The mean SDI score increased over 20 points. The IIEF- 5 was 11 and improved to 18 . Interestingly, the changes in total and free testosterone were not significant, arguably because these men were eugonadal at baseline. These results were similar to the improvements in IIEF-5 scores 2 years after bariatric surgical weight loss of $30 \%{ }^{22}$ Significant improvements in all domains (drive, erectile, ejaculatory, problem assessment and satisfaction) of the Brief Sexual Function Inventory (BSFI) were also demonstrated in a 2-year study of bariatric weight loss. ${ }^{23}$ Mean age in this study was 48 years (range 1975 years), and multivariate analysis demonstrated that the amount of weight loss was predictive of the degree of improvement in every BSFI domain.

Perhaps one of the more convincing arguments to demonstrate to health care professionals and patients that weight loss is pertinent to immediate overall and sexual health are the short- and long-term data on bariatric surgery. ${ }^{24,25}$ This paradigm is of course not used to advocate for more bariatric procedures in obese men, but to provide a tangible example how weight loss alone can dramatically change disease risk and multiple health parameters over short and long time periods. It is of interest that reviews of past studies evaluating bariatric surgery and changes in male sex hormones found improvements in sexual health or testosterone levels in virtually every investigation conducted. In some cases, testosterone increases would have been tantamount to the benefits of receiving androgen replacement therapy. ${ }^{25}$ For example, a study by Hammoud et al. ${ }^{26}$ found a mean significant increase in total testosterone of $15.3-47.6 \mathrm{ng} \mathrm{ml}^{-1}$ (increase of $310 \mathrm{ng} \mathrm{dl}^{-1}$ in non-metric units) and free testosterone (45.2 $\mathrm{pg} \mathrm{ml}^{-1}$ ) 2 years after a Roux-en-Y gastric bypass. Dissatisfaction with sexual quality of life correlated with increases in obesity and difficult sexual performance and low libido inversely correlated with total and free testosterone.

Some critics of lifestyle changes may point toward a few select studies that demonstrated no benefit or even negative impacts on sexual health with significant weight loss regardless of the method used. ${ }^{27,28}$ However, what needs to be emphasized is that some of these same rare negative studies found other diverse quality of life benefits with weight loss. ${ }^{29} \mathrm{~A}$ failed attempt to improve sexual health via lifestyle should be just another clinical indicator to begin to introduce other conventional medicine options to improve sexual function, ${ }^{27}$ similar to what is done in other medical specialties, such as cardiology or rheumatology or orthopedics. ${ }^{1,2}$

On the basis of the studies highlighted here, it appears that weight loss alone of $5 \%-10 \%$ that does not include rigorous exercise in overweight or obese non-diabetic or diabetic men can result in potential improvements in sexual, reproductive and urinary function in a short period of time. This statement should be added to urological sexual health guidelines.

\section{EXERCISE AS A FIRST-LINE PREVENTION AND TREATMENT OPTION}

In one of the only meta-analyses of exercise and ED published, which included seven cross-sectional analyses, there was an estimate of an approximate $40 \%-60 \%$ reduction in ED risk with moderate to higher levels of exercise. ${ }^{30}$ In men less than 40 years of age, being sedentary was associated with a significantly increased risk of ED in the domains of erectile function, orgasm function and intercourse satisfaction. Greater amounts of exercise improve sexual function in younger men even after control for multiple confounding variables. ${ }^{31}$ A sedentary lifestyle has also been correlated with an increased risk of ED in multiple notable, diverse prospective epidemiological studies regardless of age or age range, such as the Massachusetts Male Aging Study, ${ }^{32}$ the Health Care Professionals' Follow up Study ${ }^{33}$ and a Vienna health screening project. ${ }^{34}$ Cardiovascular fitness and exercise frequency may also provide reductions in risk or severity of ED of $40 \%-50 \%$ and even higher in men with diabetes and in men with other comorbidities such as hypertension. ${ }^{35,36}$

How much exercise should be recommended? A population-based cross-sectional study of ED in Hong Kong that included 1506 men aged $26-70$ years found that being physically active $\left(\geqslant 1000 \mathrm{kcal} \mathrm{week}^{-1}\right)$ reduced the risk of ED in men who were obese. ${ }^{37}$ Moderate intensity exercise $\left(\geqslant 150\right.$ min week ${ }^{-1}$ ) was associated with maintaining healthy erectile function, and both a low physical activity level and a high WC were independently associated with ED in an evaluation of 3941 men. ${ }^{38}$ Another study of 674 men aged $45-60$ years found an $83 \%$ reduction in severe ED in those who engaged in at least $3000 \mathrm{kcal}_{\text {week }}{ }^{-1}$ of physical activity compared with those who did less. ${ }^{39}$ A comparative case-control study of metabolic syndromes found a significant $88 \%$ reduction in the risk of ED for middle-aged men who engaged in greater than $400 \mathrm{kcal} \mathrm{day}^{-1}$ of exercise. ${ }^{40}$ If a pill had this kind of data to reduce or improve ED, would it be included in sexual health guidelines?

Also intriguing are the new data suggesting that lifestyle changes could significantly enhance the benefits of conventional medical ED options. ${ }^{41}$ In one randomized, open-label study of 60 patients with $\mathrm{ED}$, half of the participants took PDE- 5 inhibitors and the other half combined the pill with regular exercise for 3 months. Men in this trial were overall inactive at baseline and were instructed to choose any form of exercise (along with intensity and duration information) if they were in the exercise group. Men with a history of radical pelvic surgery were excluded. The mean age and BMI of the participants were 50 years and 27 (overweight), respectively. A significant improvement was observed in all aspects of the IIEF-15 except the orgasm domain for men who exercised three or more hours a week compared with the group who used only the ED pill. Erectile function, confidence, sexual desire, intercourse satisfaction and total satisfaction were all significantly improved in the exercise group over the PDE-5 alone group. There was no significant difference in testosterone levels between the groups, but within the exercise group only, there was an increase in testosterone. Frequency of intercourse was nonsignificantly greater in the exercise group than in the pill alone group. It is interesting that no PDE-5 inhibitor has ever shown a consistent benefit for libido, ${ }^{42}$ but when combined with exercise, this specific benefit occurred. ${ }^{41}$ Thus, recommending at least $30 \mathrm{~min}$ of aerobic exercise per day on average with a minimum of 300-500 calories utilized during each physical activity session should be mentioned in ED guidelines. 
Multiple mechanisms of action have been proposed as to how exercise could improve sexual function, and these suggested benefits always seem to revolve around heart-healthy parameters. ${ }^{33,40,42-45}$ For example, improved cardiovascular fitness, endothelial function and neurotransmitter release; reduced sympathetic overdrive, inflammatory response and fibrinogen; and psychological benefit have all been demonstrated with exercise in laboratory and human studies. Resting heart rate and heart rate recovery may be novel factors associated with ED. ${ }^{46,47}$ In fact, an increase in resting heart rate may also be associated with a higher rate of mortality from heart disease and all causes. ${ }^{48}$ Despite encouraging research on novel cardiovascular risk marker reductions that may improve erectile function, ${ }^{49}$ more simplistic markers such as resting heart rate will always appear to be needed to gauge the success of an exercise program. ED guidelines should also include daily exercise that is adequate to maintain a healthy weight, waist circumference and heart rate.

The medical literature is replete with data demonstrating the correlation between depression and other psychological issues and sexual dysfunction, ${ }^{50}$ and the large negative impact of certain psychological medications on ED is also well known, including the finding that $60 \%-70 \%$ of patients on antidepressants experience adverse sexual effects. ${ }^{51}$ Additionally, multiple meta-analyses have demonstrated that exercise reduces depressive scores with and without conventional medicine, ${ }^{52-54}$ which again begs the question similar to sexual function guidelines as to why aerobic and resistance activity is not a part of conventional sexual dysfunction guidelines. Eliminating critically beneficial mental health medications is obviously not the goal, but rather, if exercise becomes standard treatment, enhancing medication compliance, improving quality of life and reducing sexual dysfunction might be the end result. At least the impact of exercise on mental health should not be understated. A recent Cochrane review analyzed 25 randomized controlled trials in 1505 patients diagnosed with major depressive disorder (MDD) and found a potential clinical impact on depression scores that in some cases mirrored the response to conventional drug treatment. ${ }^{53}$ A multitude of mechanisms as to how exercise reduces depression have been proposed, such as cortisol reduction, neurotransmitter changes, diversion from negative thoughts, social contact and reductions in sympathetic overload that can reduce anxiety and agitation. ${ }^{52-54}$ Limitations with exercise and depression are arguably compliance rates, methodology of trials, whether tachyphylaxis occurs in the long term and detrimental effects of excessive physical activity. Regardless, at the very least, cognitive therapy and exercise have both been found to be equivalent in terms of mental health benefit, and psychological interventions appear to be effective for the treatment of certain forms of ED. ${ }^{55}$

\section{OTHER INDIVIDUAL LIFESTYLE CHANGES}

The list of prescription and OTC medications that continue to have some negative impact of ED continues to increase, ${ }^{56-59}$ which is why polypharmacy also must be thoroughly addressed and could be considered a lifestyle modification itself. Hair loss products and some benign prostatic hyperplasia products, ${ }^{58}$ pain medications ${ }^{59}$ and other commonly used medications may reduce sexual function, and these effects should be discussed with patients on a regular basis. ${ }^{56}$ This should provide some motivation to utilize lifestyle changes to potentially reduce the risk of ED caused by these medications or to be careful about adding medications including dietary supplements unless a careful analysis of risk $v s$. benefit has been completed.

Other available products that can impact sexual function are more obvious but still require regular reiteration from a clinician in terms of ongoing evidence-based data. For example, a meta-analysis of 19 studies published between 1980 and 2001 found a consistently higher rate of ED for smokers than for non-smokers. ${ }^{60}$ Tobacco and ED continue to be correlated in recent studies, and this includes both the direct use of tobacco and second-hand smoke exposure. ${ }^{61,62}$ Over $20 \%$ of the cases of ED in some countries may be due to tobacco use. ${ }^{63}$ Lung cancer is still the number-one cause of cancer deaths globally, ${ }^{64}$ which should provide patients some impetus to quit along with the relationship of smoking with common morbidities such as sexual dysfunction. Clinicians should be willing to provide tobacco users with effective avenues for medical cessation, because health care professional involvement increases the probability of cessation from 3\%-5\% over a 1 -year period to approximately $25 \%$. $^{65}$

The risk of ED also exists with excessive alcohol consumption, especially when combined with tobacco use or other heart-unhealthy behaviors. ${ }^{66,67}$ However, alcohol in moderation or infrequent consumption may provide some protection against ED. ${ }^{68,69}$ Thus, clinicians should emphasize moderate or no intake for adequate sexual health.

The largest production and release of testosterone for men during a 24-h period occurs during sleep. ${ }^{70}$ Middle-aged men secrete less testosterone during sleep than do younger men. ${ }^{71}$ Also, if sleep appears to be disrupted in some way, there is evidence that testosterone levels are impacted. Sleep apnea is associated with reduced testosterone levels, ${ }^{72}$ and voluntary sleep deprivation could also be a risk factor for androgen deficiency. A recent novel study of 10 men with a mean age of 24 years and BMI of 23.5 was conducted to determine the impact of voluntary sleep restriction. ${ }^{73}$ After 1 week of $8 \mathrm{~h}$ per day of sleep at home, these individuals were allowed $10 \mathrm{~h}$ per night for 3 days in a sleep laboratory followed by 8 straight nights of $5 \mathrm{~h}$ of sleep. Blood samples were derived every 15-30 min after a specific 10-h sleep night and after a 5 -h sleep night. During waking hours ( 8 a.m. to 10 p.m.), testosterone levels were significantly lower $(P=0.05)$ after sleep restriction, and the impact was most noticeable between 2 p.m. and 10 p.m. $(P=0.02)$. The mean reduction in testosterone was $18.4-$ $16.5 \mathrm{nmol}^{-1}\left(530-475 \mathrm{ng} \mathrm{dl}^{-1}\right)$ or approximately $10 \%-15 \%$ in most participants. Cortisol levels were not significantly different, but there was a significant $(P=0.002)$ reduction in vigor scores with sleep restriction.

Finally, it should also be noted that underweight (BMI 20 or less) may also be a risk factor for sexual dysfunction. Several past studies have examined this relationship and have indeed found a potential Ushaped correlation with BMI. ${ }^{37,66}$ This should receive further research because it may reflect a similar underlying pathology to what occurs with obesity, and/or a subclinical disease state whose early manifestations are actually reflected by alterations in sexual health perhaps similar to what has been observed with heart disease and erectile function. ${ }^{11-13}$

\section{COMPREHENSIVE LIFESTYLE CHANGES}

A unique 2-year randomized trial of regular exercise and multiple dietary changes (mirrored a Mediterranean diet) to improve ED in obese men should receive more clinical attention despite being initially published in $2004 .^{74} \mathrm{~A}$ total of 110 obese men with a mean BMI of 3637 , waist-to-hip ratio of 1.01-1.02 and age of 43 years participated. The mean IIEF score at baseline ranged from 13 to 14 out of 25 , and men in this trial were without diabetes, high cholesterol or hypertension. A total of 55 men were included in an aggressive intervention group that reduced calories and increased physical activity via personalized dietary counseling, exercise advice, dietary changes and regular appointments with a nutritionist and personal trainer. Another group 
of 55 men were in the control group and were given general information about exercise and healthy food choices. After 2 years, multiple, diverse and significant mean changes occurred in the intervention group compared with the placebo group. These are summarized in Table 2.

ED scores increased significantly $(P=0.008)$ compared with controls by 3 points. A total of 17 men in the intervention group actually reported an erectile score of 22 or higher (normal function). Thus, approximately $33 \%$ of the men with ED in this study regained normal erectile function within 2 years, and the majority of men experienced at least some improvement in sexual function and a simultaneous reduction in the risk of common cardiovascular disease markers. Multivariate analysis demonstrated that several changes were independently and significantly associated with a higher rate of improved erectile health on the IIEF, including a lower BMI or BMI reduction, increased physical activity and lower C-reactive protein levels. The comprehensive lifestyle intervention had one major limitation, which was the lack of evaluation of psychological factors, because it is also plausible that these lifestyle changes improved mood and self-esteem, which could have been another mechanism for improved erectile function.

Another large randomized study by this same research group utilizing a similar intervention protocol was also published in $2004 .^{75}$ This trial was also conducted over a 2 -year period in patients, but in participants with metabolic syndromes. A total of 180 men and women ( $n=90$ in each group) demonstrated a large, significant resolution of metabolic syndrome prevalence (over 50\% reduction), reduction in cardiovascular risk and endothelial function improvement compared with controls. IL-6, which correlates with C-reactive protein production, was also significantly reduced in these past clinical trials. $^{74,75}$ IL-6 and hs-C-reactive protein are gaining acceptance as potential markers of cardiac and overall health, ${ }^{76}$ and perhaps erectile function, and may provide a novel mechanism for ED reduction after nerve-sparing radical prostatectomy. ${ }^{77}$ A recent follow-up from this research group of 209 men participating in these and other past clinical trials (mean age 45 years and BMI 31-32) continues to support the notion that erectile function rates can be significantly normalized (34\%-56\% of participants) in men compared with controls through comprehensive lifestyle changes alone. ${ }^{78}$ Other intensive lifestyle programs in different patient populations continue to support lifestyle interventions as a standard treatment to improve erectile health and overall health. ${ }^{79,80}$ Again, a lack of tangible sexual health benefits in men from lifestyle changes should be a clinical marker of the immediate need to add other conventional medicines as listed in the ED guidelines.

Multiple and diverse international studies over the past decade have supported and continue to support the common observation that almost every heart-unhealthy change or condition (physical inactivity, obesity, smoking, dyslipidemia, diabetes, etc.) is associated with a detrimental impact on some aspect of sexual health. Correspondingly, heart-healthy changes are tantamount to penile or sexual healthy changes. Original studies from Australia, ${ }^{81}$ Austria, ${ }^{82}$ Brazil, ${ }^{83}$ Canada, ${ }^{84}$ Egypt, ${ }^{85}$ Finland, ${ }^{86}$ France, ${ }^{87}$ Iran, ${ }^{88}$ Israel, ${ }^{89}$ Italy, ${ }^{83}$ Japan, ${ }^{83}$ Jordan, ${ }^{90}$ Korea, ${ }^{91}$ Malaysia, ${ }^{83}$ Mexico, ${ }^{92}$ Portugal, ${ }^{93}$ Qatar, ${ }^{94}$ Saudi Arabia, ${ }^{95}$ Singapore, ${ }^{96}$ Thailand ${ }^{97}$ and the United States ${ }^{98}$ are just a few of the multitude of international publications that demonstrate the importance of lifestyle changes on sexual health. These past clinical studies have included men with diverse health backgrounds including normal to obese BMIs, which suggests that all men, regardless of age should be informed about this correlation. Although, it is recognized that the most profound evidence from weight loss interventions alone in randomized trials currently exists especially for obese males. ${ }^{19,74}$

It is time for erectile and sexual dysfunction guidelines to recognize and reward the cumulative research efforts completed on lifestyle changes over the past decade and more. It is time to also insert simplistic general and specific advice for clinicians and patients in these same guidelines, and a few past reviews have inserted some general recommendations among a larger topical manuscript, which represented a notable initiative. ${ }^{99}$ More specific suggestions derived from this article and from other sources are found in Table $3 .^{42}$

Table 2 Statistically significant health parameter changes in the lifestyle intervention group compared with controls after 2 years: results of a randomized controlled trial of the effect of lifestyle changes on erectile dysfunction ${ }^{\mathrm{a}}$

\begin{tabular}{|c|c|c|c|}
\hline Health parameter & $\begin{array}{l}\text { Baseline values of lifestyle } \\
\text { intervention group only (mean) }\end{array}$ & $\begin{array}{l}\text { After 2-year lifestyle intervention } \\
\text { group only values (mean) }\end{array}$ & $\begin{array}{c}\text { Corrected difference in mean } \\
\text { change for lifestyle vs. control group } \\
\text { at the end of the 2-year trial }\end{array}$ \\
\hline BMI & 36.9 & 31.2 & -5 \\
\hline WHR & 1.02 & 0.93 & -0.08 \\
\hline Weight (kg) & 103 & 88 & -13 \\
\hline Total cholesterol $\left(\mathrm{mmol}^{-1}\right)$ & 5.51 & 5.22 & -0.34 \\
\hline HDL cholesterol (mmol I-1) & 1.01 & 1.24 & +0.23 \\
\hline Triglycerides $\left(\mathrm{mmol} \mathrm{I}^{-1}\right)$ & 1.91 & 1.69 & -0.39 \\
\hline Glucose $\left(\mathrm{mmol} \mathrm{I}^{-1}\right)$ & 5.72 & 5.27 & -0.5 \\
\hline Insulin (uU ml $\left.\mathrm{I}^{-1}\right)$ & 21 & 14 & -5.0 \\
\hline IL-6 (pg ml $\left.\mathrm{l}^{-1}\right)$ & 4.5 & 3.1 & -1.5 \\
\hline $\mathrm{CRP}\left(\mathrm{mg} \mathrm{l}^{-1}\right)$ & 3.3 & 1.9 & -1.4 \\
\hline Systolic BP (mmHg) & 127 & 124 & -2 \\
\hline Diastolic BP (mmHg) & 86 & 82 & -4 \\
\hline Physical activity level (min week ${ }^{-1}$ ) & 48 & 195 & +114 \\
\hline Total daily calorie intake (calories day ${ }^{-1}$ ) & 2340 & 1950 & -340 \\
\hline Fiber intake (g) & 15 & 25 & +9 \\
\hline Saturated fat ( $\%$ calories) & 14 & 9 & -5 \\
\hline Ratio of omega- $6: 3$ & 12 & 6 & -5 \\
\hline
\end{tabular}

Abbreviations: BMI, body mass index; BP, blood pressure; CRP, C-reactive protein; HDL, high-density lipoprotein; WHR, waist-to-hip ratio.

${ }^{a}$ Data are derived from Esposito et al. ${ }^{74}$ 
Table 3 Suggested comprehensive general and specific lifestyle changes with clinical evidence to be included in sexual dysfunction guidelines and that could be utilized with or without conventional medicines by health care professionals and patients ${ }^{a}$

\begin{tabular}{|c|c|}
\hline Lifestyle/health parameter & General recommendation for men \\
\hline Alcohol & Eliminate or reduce when dieting; otherwise, 1-2 standard drinks per day maximum \\
\hline Calories (dietary) & Reduce by $100-600$ calories day ${ }^{-1}$ according to weight-loss goals \\
\hline Dairy & Low-fat and low-calorie dairy \\
\hline Carbohydrates & Reduce simple sugars and increase consumption of complex carbohydrates including fiber (see below) \\
\hline Cardiovascular risk markers & $\begin{array}{l}\text { Review the overall numbers to achieve or maintain heart-healthy parameters (blood pressure, cholesterol, } \\
\text { glucose, heart rate, C-reactive protein, etc.). Heart health=sexual health. }\end{array}$ \\
\hline Exercise & $\begin{array}{l}\text { Approximately } 30 \text { min minimum per day on average or at least 300-500 calories expended per daily } \\
\text { physical activity. Resistance exercise should also occur 1-2 times a week. }\end{array}$ \\
\hline Fat (dietary) & $\begin{array}{l}\text { Reduce saturated fat to less than } 10 \% \text { calories, increase intake of monounsaturated and } \\
\text { other healthy fat (omega-3 for example) }\end{array}$ \\
\hline Fiber & $\begin{array}{l}\text { 20-30 } \text { g day }^{-1} \text { of a combination of soluble and insoluble fiber, or } 15 \mathrm{~g} \text { of fiber per } 1000 \mathrm{kcal} \text { consumed per } \\
\text { day }\end{array}$ \\
\hline Fruits and vegetables & Several servings per day of whole fruits and vegetables (not processed) \\
\hline Meat & $\begin{array}{l}\text { Lean, game and grass-fed meats should be encouraged over high-saturated-fat meat, and moderate to } \\
\text { minimal consumption should also be encouraged. }\end{array}$ \\
\hline Medications (prescriptions and supplements) & Review the list on a regular basis to determine the impact on sexual health \\
\hline Mental health (depression/stress/anxiety) & Awareness and discussion and evaluation on a regular basis \\
\hline Nuts and seeds & Several servings a week (high in fiber, magnesium, potassium and healthy fats) \\
\hline Omega-3 fatty acids & $\begin{array}{l}\text { Consume healthy fatty fish at least twice a week and increase consumption of plant omega-3 (chia, } \\
\text { flaxseed, soy, etc.) }\end{array}$ \\
\hline Processed food & Choose unprocessed options when possible (whole fruit instead of juice, whole grain, etc.) \\
\hline Protein consumption & $\begin{array}{l}0.8-1.0 \mathrm{~g} \mathrm{~kg}^{-1} \text { of body weight; utilize low-calorie whey, casein, egg white or plant (soy, etc.) protein } \\
\text { powders if needed }\end{array}$ \\
\hline Sleep & $\begin{array}{l}\text { A total of } 6-8 \mathrm{~h} \text { on average per night and become educated on specific sleep issues (apnea, nocturia, } \\
\text { snoring, etc.) }\end{array}$ \\
\hline Sodium (or potassium/sodium ratio) & $\begin{array}{l}\text { Consume less than } 2500 \text { or } 1500 \text { mg day }^{-1} \text { if salt-sensitive or highly salt-sensitive; otherwise, choose } \\
\text { foods with high potassium/sodium ratio (>2:1) (unsalted nuts, seeds, fruits, vegetables, etc.) }\end{array}$ \\
\hline Tobacco (including cigars, smokeless and secondhand/passive) & Eliminate or educate on current cessation options \\
\hline Weight and waist size & $\begin{array}{l}\text { Maintain a healthy weight/waist, or a } 5 \%-10 \% \text { weight reduction over several years is associated with } \\
\text { sexual and overall health improvements. Become educated on local weight-loss medical organizations } \\
\text { and publications. }\end{array}$ \\
\hline
\end{tabular}

${ }^{a}$ Discussion with a hospital, clinic or community nutritionist should also be encouraged, and a goal of reducing cardiovascular risk to as close to zero as possible with the primary care doctor or specialist should be discussed with each patient.

\section{Panax ginseng}

Over a decade ago, the stated guidelines of numerous conventional medicine disciplines and specialty groups evolved to include not just lifestyle interventions but also cost-effective and seemingly safe in moderation and effective OTC dietary supplement options (plant stanols, calcium, vitamin $\mathrm{D}$, fish oil, etc.). ${ }^{1,2}$ This has not occurred in the area of sexual dysfunction, ${ }^{3,100}$ which may be partially understandable owing to the notorious record of some OTC options, ${ }^{101-103}$ but at the same time, such negative historical results should not cloud objectivity over the products and methods that have some past and current scientific merits.

Ginseng actually refers to the root of several species in the genus Panax, of which Panax ginseng is arguably one of the most widely utilized species and is native to Asian countries such as China and Korea. ${ }^{104-107}$ Panax ginseng has a medical history stretching over 5000 years. Ginsenosides (also known as ginseng saponins or glycosylated steroidal saponins), which are unique to the Panax species, are the primary active ingredients in ginseng, and more than 30 different ginsenosides have been isolated from the root of Panax ginseng. ${ }^{104-107}$ Although ginseng contains other miscellaneous molecular compounds, the individual and collective ginsenosides appear to be the generally agreed upon clinically efficacious or active ingredients. ${ }^{104-111}$ Ginsenosides have multiple mechanisms of action, and each ginsenoside may have tissue-specific impacts. ${ }^{108-111}$
Over time, the content of ginsenoside standardized extracts used in studies has varied, from approximately $4 \%$ ginsenosides in the $1990 \mathrm{~s}$ to $4 \%-7 \%$ ginsenosides in the mid-2000s, and higher standardized extracts are offered today ( $>8 \%$ for example). ${ }^{112,113}$ Thus, the ginsenoside content must be kept in mind when comparing different efficacy doses from clinical trials. When the ginsenoside concentration is isolated, it appears to elicit the same or better results than the sum of the total ginseng components, ${ }^{113}$ which again supports the accepted theory that ginsenosides are the active medical components of Panax ginseng. ${ }^{104-113}$ Additionally, Panax ginseng has been shown to be a cost-effective intervention, especially when comparing it to other available sexual dysfunction options. ${ }^{108}$

\section{RANDOMIZED CLINICAL TRIALS OF PANAX GINSENG AND SEXUAL FUNCTION}

Perhaps one of the most influential endorsements for ginseng and male sexual function was a recent clinical evidence guideline of conventional and alternative medicines written by Khera and Goldstein. ${ }^{114}$ The authors reviewed Panax ginseng data from six randomized trials conducted over a period of approximately 15 years that included a total of 349 men. The investigators found that ginseng significantly $(P<0.00001)$ improved erectile function compared with placebo over 4-12 weeks. Approximately $58 \%$ of men experienced an improvement in some aspect of sexual function compared with $20 \%$ of men who received the placebo. No other dietary supplement was 
recommended among all of the conventional therapies reviewed. Ginseng was found to have 'moderate-quality evidence' and the investigators concluded that ginseng is 'likely to be beneficial' in men with ED of any etiology. The final clinical evidence-based guideline provided in this review stated that 'Ginseng is a traditional Asian remedy with rare adverse effects in the recommended dose of $0.5-2.0$ grams daily'. Interestingly, this systematic review noted that the authors had not yet evaluated the recent concentrated ginsenoside randomized trial by Park and colleagues ${ }^{115}$ that was published in Korean in the Korean Journal of Urology, and was being translated. One of the present authors (Moyad) has had the study by Park and colleagues translated into English, and it arguably provides the best clinical data to date for a dietary supplement compared with placebo over 8 weeks. This was a multicenter, randomized, double-blind, placebo-controlled study of 69 participants that used a highly concentrated ginsenoside but lowdose overall ginseng product. ${ }^{115}$ The primary endpoint was the response to the erectile function domain of the IIEF questionnaire at baseline and 8 weeks. The other domains of the IIEF were secondary endpoints, and safety was monitored. Every single sexual health domain from the IIEF-15 was significantly improved by Korean ginseng compared with placebo: erectile function (primary endpoint), sexual desire, orgasmic function, intercourse satisfaction and overall satisfaction. Furthermore, every single question on the IIEF ( 15 out of 15) was improved significantly. The sexual desire domain, frequency and degree of sexual desire were all significantly increased $(P<0.001)$. In other words, both the primary and the secondary endpoints significantly favored ginseng over placebo. Additionally, there were no significant differences in adverse events reported for ginseng compared with placebo. ${ }^{115}$ The results of this trial should strengthen the clinical evidence for Panax ginseng and the evidence that concentrated ginsenosides are the active or effective ingredients in ginseng.

Another recent systematic reviews of alternative medicines for sexual function by Ernst et al. ${ }^{116}$ arrived at a similar conclusion as the Khera and Goldstein review. ${ }^{114}$ The qualitative methods utilized from past clinical trials were evaluated by two independent experts, and the only dietary supplement that received a cautiously positive conclusion with no overt safety issues was again, Panax ginseng. Another notable systematic review published in 2008 should also be mentioned because this was a review of all randomized data from Panax ginseng trials up to that time period. ${ }^{117}$ This meta-analysis again emphasized the significant $(P<0.00001)$ effect of ginseng on erectile function, which agrees with the authoritative publication of Khera and Goldstein. ${ }^{114}$ Subgroup analyses also found a significant $(P=0.001)$ impact of ginseng on the psychogenic etiology of sexual dysfunction. The authors stated that adverse events or side effects were 'scarce and those that were reported were mild'. No significant side effects compared with placebo were reported. According to this review, the quality of future trials must be improved, but the fact that numerous randomized trials met the inclusion criteria set by these investigators up to 2008 is notable.

Thus, the three most recent comprehensive reviews of conventional or alternative medicine in the treatment of sexual dysfunction all arrived at a similar conclusion: ${ }^{114,116,117}$ ginseng is an option for men at a variety of dosages and ginsenoside concentrations. Furthermore, the trial with arguably one of the highest standards in terms of methodology and clinical benefits has yet to be evaluated or added to these clinical evidence guidelines. ${ }^{115}$ Onset of action or efficacy of ginseng could arguably occur within days to months. ${ }^{115,117}$ The time period is variable and requires further elucidation. In our opinion, onset is not as rapid on average as PDE- 5 inhibitors, but the impact on libido, comparative cost and safety affords ginseng its own set of advantages.

\section{LABORATORY DATA/MECHANISMS OF ACTION}

The ample laboratory data for ginseng and ginsenosides suggest multiple mechanisms of action of ginseng. In cultured bovine endothelial cells, ginsenosides were shown to stimulate the conversion of [14C]Larginine to [14C]L-citrulline and to promote vasorelaxation. ${ }^{118}$ More specific studies in rabbit corpus cavernosum tissue or in an in vitro tissue model continue to support the release of endogenous nitric oxide (NO) via the addition of ginsenosides. ${ }^{119-121}$ In an in vitro tissue bathing model, ginsenosides $\left(250,500\right.$ and $\left.750 \mu \mathrm{g} \mathrm{ml}^{-1}\right)$ caused relaxation of the corpus cavernosum in a concentration-dependent manner. Furthermore, acetylcholine-induced relaxation of tissue was increased in the presence of ginsenosides.

In a study of a longer duration, in vitro and in vivo mechanistic studies in rabbits and rats were completed over 3 months. ${ }^{122}$ In that study, relaxation effects were significantly $(P<0.01)$ increased by Panax ginseng, as evidenced by intracavernosal pressure and the precontraction of the tissue strips with several compounds. Those authors concluded that long-term administration of Panax ginseng enhanced erectile capacity and that its action was mediated by 'endotheliumderived relaxing factor' (also known as NO) and peripheral neurophysiological enhancement.

A recent laboratory investigation of a primary ginsenoside (Rg1) from Panax ginseng showed significantly increased mounting and pelvic thrusting frequency and intromission numbers of male mice. ${ }^{123}$ Ginseng components also increased testosterone, cyclic guanosine monophosphate accumulation and NO release. It is also of interest that a past human interventional mechanistic study of 12 males demonstrated that a single oral administration of Panax ginseng water extract $(500 \mathrm{mg}$ per $50 \mathrm{~kg})$ significantly $(P<0.05)$ increased NO levels for about a 2 -h period after 45 min of administration. ${ }^{124}$ Ginseng increased NO in exhaled breath and reduced blood pressure and heart rate. The correlation between NO levels and heart rate was significant $(P<0.01)$. Panax ginseng may be useful for treating high blood pressure and pulmonary vascular obstruction via improvement in $\mathrm{NO}$ concentrations and potentially through vasodilation. No significant side effects were reported in this publication. This may also partially explain the potential mechanism of action whereby certain ginsenosides may provide some cardiovascular protection. ${ }^{120}$

Gamma-aminobutyric acid receptor binding of ginsenosides also increases the affinity of specific flunitrazepam binding and decreases the affinity of specific baclofen binding. ${ }^{125}$ Ginsenosides compete with agonists for binding to gamma-aminobutyric acid-A and gammaaminobutyric acid-B receptors, which could also explain a central mechanism of action impacting desire or arousal. Anxiolytic effects have also been demonstrated in mice and maze models. ${ }^{126}$ Ginseng and ginsenosides have been shown to favorably impact striatal dopaminergic activity and dopamine receptors. ${ }^{127}$ Ginseng may exert a direct effect on the hypothalamus or pituitary to also suppress prolactin release, ${ }^{128}$ but these hormonal changes must be subtle if they occur because past clinical trials measuring hormonal changes in men did not find significant or consistent increases in prolactin or testosterone. ${ }^{129}$ Still, the neurotransmitter or centrally acting effects of ginsenosides require further investigation in humans, because animal models continue to demonstrate notable antidepressant effects. ${ }^{130,131}$

Other pathways that deserve investigation are the heart-healthy changes that may occur with ginseng, which theoretically could lead to an improvement in sexual function. For example, a recent 
randomized, controlled, double-blind, crossover trial of 17 healthy, fasted individuals examined the effects of Panax ginseng or its ginsenosides on arterial stiffness. ${ }^{113}$ Ginseng significantly lowered the radial augmentation index by $4.6 \%$ compared with placebo $(P=0.05)$, and the ginsenoside fraction reduced it by $4.8 \%$; no significant effect was found with the polysaccharide fraction of ginseng.

The potential improvement in multiple potential cardiovascular parameters, including glucose, lipids and blood pressure, is also of interest. ${ }^{132,133}$ Furthermore, at the time of submission of this manuscript, a Panax ginseng double-blind randomized parallel trial of 72 postmenopausal women over 12 weeks had found a significant benefit for relieving menopausal symptoms and significant reductions in lowdensity lipoprotein and carotid intima-media thickness compared with placebo without significant changes in estradiol. ${ }^{134}$

Another potential mechanism of action could be the antifatigue effect or improved energy levels with ginseng. The most interesting such study was a recent large $(n=290)$ Mayo Clinic trial of American ginseng that found sufficient improvements in cancer-related fatigue over placebo to warrant further clinical study. ${ }^{135}$ Interestingly, no side effects over placebo were found in the low $(750 \mathrm{mg})$ or higher (2000 mg) ginseng dose group. The mental or physical energy enhancing effects of ginseng are of interest in both sexes, ${ }^{136,137}$ and could theoretically explain some of the sexual health improvements.

In our opinion, one ancillary mechanism of action that appears most notable as of yet may be the neurological improvement or protection via ginsenosides from degenerative or abnormal conditions in the central or peripheral nervous system. ${ }^{138-143}$ Ginsenosides have demonstrated some antiinflammatory, antioxidant, antiapoptotic, neuronal growth factor enhancement and other mechanisms of action. It is also noteworthy that large doses of ginseng have already been utilized in patients with neuronal degenerative diseases with at least a hint of clinical efficacy, which should maintain interest in diverse neurological research with ginseng extracts. ${ }^{144,145}$ The impact of ginseng on cognition and quality of life makes ginseng an attractive agent for this type of mechanistic research in an aging population. ${ }^{146,147}$

\section{SAFETY}

The primary issue with any OTC herbal product, especially in the area of sexual function is adherence to quality control. The US Food and Drug Administration appears to have been indirectly or directly responsible for removing an estimated 70-100 products from the market in this category because of contamination, which appears to be second only to weight-loss OTC products. ${ }^{148}$ Regular testing of PDE-5-like compounds or contaminants should be the rule and not the exception. A listing of some of the analogs that can be tested by liquid chromatography mass spectroscopy is found in Figure $1 .^{148,149}$

In terms of unadulterated ginseng itself, laboratory studies have consistently found no overt safety or toxicity issues of concern. For example, Panax ginseng was recently nominated by the US National Institutes of Health to the US National Toxicology Program for assessment of its carcinogenic potential. ${ }^{150,151}$ Researchers examined chronic toxicity, tumorigenicity and safety in multiple studies in male and female mice (B6C3F1) and rats (Fischer 344). No significant safety issues were found in animals in the 2-week, 3-month or 2-year gavage studies. The results of the US National Toxicology Program acute and chronic toxicity and tumorigenic bioassays found Panax ginseng to be neither toxic nor tumorigenic even when administered at a dose of $5000 \mathrm{mg} \mathrm{kg}^{-1}$.
Past laboratory studies investigating the impact of Panax ginseng on sexual function also noted no safety issues of concern. For example, in the most recent investigation, the researchers reported no animal (mouse) mortality even with doses up to $20 \mathrm{~g} \mathrm{~kg}^{-1}$ for 10 days. ${ }^{123}$ In another ancillary study by this same group, no signs of toxicity were observed in beagle dogs that were treated with a primary ginsenoside (Rg1) at a dose of $500 \mathrm{mg} \mathrm{kg}^{-1}$ by mouth daily for 5 months.

The consistency of safety data from human studies is also notable and is derived from a variety of sources. For example, a 2002 analysis included a systematic review from five electronic databases and all articles with original data on adverse events and drug interactions with Panax ginseng. ${ }^{152}$ Information was also requested from 12 manufacturers of preparations of ginseng, the spontaneous reporting of the World Health Organization, and national drug safety bodies. No language restrictions were imposed. The incidence of side effects of ginseng was found to be similar to that of placebo. A 2009 update to this manuscript reached a similar conclusion and stated that the potential for drug-ginseng interactions is 'low' and the concern over other medications is mostly based on isolated case reports. ${ }^{153}$

Thus, a serious, perhaps surprising concern with some herbal preparations in our opinion is the chance for them to be inappropriately and falsely tagged with an acute safety issue on the basis of isolated case reports or uncontrolled investigation without an examination of the totality of objective laboratory and clinical evidence. One perpetuated example is a 1979 observational series in a notable medical journal that associated the self-reported utilization of ginseng products with hypertension in 14 individuals after 3 months of use. ${ }^{154}$ Despite the lack of a control group and other basic methodology quality-control issues, including a lack of correction for other confounders, such as high intakes of caffeine and potentially other stimulants, this study was used by multiple authors as evidence. ${ }^{155-157}$ Yet, to our knowledge, these hypertensive effects have never been replicated since 1979 in a controlled setting. In reality, multiple randomized trials of hypertensive and non-hypertensive individuals have demonstrated no impact or a reduction in blood pressure with Panax or American ginseng and isolated ginsenosides, regardless of dose (up to $6 \mathrm{~g} \mathrm{day}^{-1}$ ) and time period (up to 3 months). ${ }^{113,124,132,158-163}$ Potential interactions with warfarin or hemostatic issues have also been suggested on the basis of case reports, ${ }^{152,153,156,164}$ but controlled studies have not been able to substantiate any consistent impact of ginseng on warfarin anticoagulation or hemostasis in general (prothrombin time, partial thromboplastin time and international normalized ratio). ${ }^{163,165-169}$ Regardless, it is plausible that coagulation effects may be subtle or tangible and need to be followed in high-risk patients, particularly because some studies have shown a reduction in warfarin's anticoagulant effect in

\begin{tabular}{ll}
\hline Acetildenafil (Hongdenafil) & Norneosildenafil \\
Aminotadalafil & Piperiacetildenafil \\
Carbodenafil & Pseudovardenafil \\
Dimethylsildenafil & Sildenafil citrate \\
Gendenafil & Sildenafil coupled \\
Homosildenafil & Tadalafil \\
Hydroxyacetildenafil & Thiodimethylsildenafil \\
Hydroxyhomosildenafil & Thiohomosildenafil \\
Hydroxythiohomosildenafil & Thiosildenafil \\
Imidazosagatnazihone & Udenafil \\
N-DesmethylAcetildenafil & Vardenafil \\
Nor-acetildenafil (Desmethylacetildenafil) & Xanthoanthrafil (Benzamildenafil)
\end{tabular}

Figure 1 A list of potential drug-like contaminants that could be utilized to adulterate herbal medicines touted for sexual health. 
healthy individuals not normally on this medication when acutely tested with American ginseng. ${ }^{170}$ On the other hand, it is also plausible that some of the favorable effects of Panax ginseng on sexual and cardiac function may be due to some antiplatelet activity. ${ }^{171}$ Regardless, over 45 years of Medline publications have failed to note a serious toxic event or even a case study on the topic of ginseng alone and coagulation issues. ${ }^{172}$

What final conclusions can be made concerning specific safety issues with Panax ginseng? Adulteration of ginseng with multiple prescription medications could explain some of the unexplained side effects in some past reports. ${ }^{112,173,174}$ Standardization of ingredients, primarily the ginsenoside content, is important to ensure safety, quality control and efficacy. ${ }^{112}$ Still, no controlled trials or systematic reviews or meta-analyses have reported any consistent, significant side effects over a variety of dosages and time periods. ${ }^{112-117,146,152,153,175,176}$ Furthermore, no long-term and intensive laboratory or animal studies have found a single consistent and significant issue of concern. ${ }^{150,151}$ Past human studies of ginseng and sexual health have reported gastrointestinal side effects, ${ }^{114-117}$ for example, stomach upset, but these were not reported at a rate significantly higher than the rate for placebo. Ingesting ginseng with a meal seems more appropriate because of potential gastrointestinal issues with any oral intervention or placebo, and there are no reports that ginseng is less or more efficacious in this scenario. In our opinion, more rigorous monitoring of ginseng safety in clinical trials should be conducted to provide some clarity on potential adverse events.

What about other positive impacts outside of sexual health derived from the ingestion of Panax ginseng, for example, the previously mentioned positive preliminary data reviewing five clinical trials on cognition? ${ }^{146}$ Such effects deserve mention as a testament to safety in Panax ginseng studies and as a reason that some patients may be better suited for a ginseng product compared with other agents or a lower dose of another agent in the area of sexual health. The potential prevention and treatment effects of ginseng on cold and flu-like symptoms, especially past studies of American ginseng in the pediatric and adult populations, are also garnering attention because of safety and past efficacy. ${ }^{177-179}$

Several other dietary supplement compounds are generating data, ${ }^{180-185}$ but Panax ginseng has arguably garnered the longest and most impressive history to date of any OTC product. The 35-year history of published basic science studies and the over 15-year history of approximately 10 randomized trials showing that Panax ginseng and its ginsenosides have potential efficacy in diverse areas of male sexual health is a real testament to past researchers. ${ }^{114-117,175,176}$ In the area of female sexual health, past basic science and recent clinical data for ginseng should also be garnering some interest. ${ }^{186-189}$

\section{CONCLUSIONS}

The primary question then left to ponder is what is the minimal threshold for any lifestyle change and/or a supplement to receive any relevant form of endorsement in clinical guidelines or in any clinical recommendation document? The omission of lifestyle changes and/or ginseng from authoritative clinical guidelines is perplexing and belittles or deflates interest in an area of medicine that should ideally serve to empower patients with a diversity of options. Also, it perpetuates the myth that some clinicians are biased and not open to or educated about cost-effective, safe and reasonably efficacious options apart from prescription medications, regardless of the available data or overall benefit-to-risk ratio. This perception, prejudice or obstaclewhatever this antiquated practice is called-has been overcome in multiple specialty areas of medicine over the past decade, ${ }^{1,2}$ but why not urology? It is our hope and intention that this type of thinking must and will change.

The idea that effective prescription pills with an average cost that is 20-40 times that of ginseng and with a definitive number of minor and serious toxicity and compliance issues should be the only acceptable ingestible option for patients has seemed odd and counterintuitive for a considerable amount of time. ${ }^{190}$ Also, what about researching the possibility of combining prescriptive and OTC agents for synergistic benefits (function and libido for example)?

Finally, what will be the excuse of experts if future ED guidelines do not begin to take lifestyle and/or supplement interventions seriously? The end result might be that some health care professionals and patients will construe this lack of emphasis as a sufficient reason or excuse to become completely dependent only on more invasive extrinsic mechanisms, instead of applying or teaching basic methods whereby the amelioration of ED is partially or completely achievable through intrinsic or more personalized lifestyle pathways. Perhaps, this has already happened? ${ }^{100,191}$

\section{COMPETING FINANCIAL INTERESTS}

Dr Moyad reports receiving royalties from Guthy Renker LLC for formulating a male sexual health supplement that contains multiple components including Panax ginseng. Dr Park reports no relevant commercial interest.

1 National Cholesterol Education Program (NCEP) Expert Panel on the Detection, Evaluation, and Treatment of High Blood Cholesterol in Adults (Adult Treatment Panel III). Third Report of the National Cholesterol Education Program (NCEP) Expert Panel on Detection, Evaluation, and Treatment of high blood cholesterol in Adults (Adult Treatment Panel III) final report. Circulation 2002; 106: 3143-421.

2 Brown JP, Josse RG; Scientific Advisory Council of the Osteoporosis Society of Canada. 2002 clinical practice guidelines for the diagnosis and management of osteoporosis in Canada. CMAJ 2002; 167(10 Suppl): S1-34.

3 Hatzimouratidis K, Amar E, Eardley I, Giuliano F, Hatzichristou D et al. Guidelines on male sexual dysfunction: erectile dysfunction and premature ejaculation. Eur Urol 2010; 57: 804-14.

4 Pischon $T$, Boeing $H$, Hoffman $K$, Bergmann $M$, Schulze MB et al. General and abdominal adiposity and risk of death in Europe. N Engl J Med 2008; 359: 2105-20.

5 Moyad MA. Current methods used for defining, measuring, and treating obesity. Semin Urol Oncol 2001; 19: 247-56.

6 Pischon T, Boeing $\mathrm{H}$, Weikert S, Allen N, Key T et al. Body size and risk of prostate cancer in the European prospective investigation into cancer and nutrition. Cancer Epidemiol Biomarkers Prev 2008; 17: 3252-61.

7 Zabelina DL, Erickson AL, Kolotkin RL, Crosby RD. The effect of age on weight-related quality of life in overweight and obese individuals. Obesity (Silver Spring) 2009; 17: 1410-3.

8 Bacon CG, Mittleman MA, Kawachi I, Giovannucci E, Glasser DB et al. Sexual function in men older than 50 years of age: results from the Health Professionals follow-up study. Ann Intern Med 2003; 139: 161-8.

9 Riedner CE, Rhoden EL, Ribeiro EP, Fuchs SC. Central obesity is an independent predictor of erectile dysfunction in older men. J Urol 2006; 176: 1519-23.

10 Esposito K, Giugliano F, Martedi E, Feola G, Marfella R et al. High proportions of erectile dysfunction in men with the metabolic syndrome. Diabetes Care 2005; 28 : 1201-3.

11 Walczak MK, Lokhandwala N, Hodge MB, Guay AT. Prevalence of cardiovascular risk factors in erectile dysfunction. J Gend Specif Med 2002; 5: 19-24.

12 Fung MM, Bettencourt R, Barrett-Connor E. Heart disease risk factors predict erectile dysfunction 25 years later: the Rancho Bernardo Study. J Am Coll Cardiol 2004; 43: 1405-11.

13 Thompson IM, Tangen CM, Goodman PJ, Probstfield JL, Moinpour CM et al. Erectile dysfunction and subsequent cardiovascular disease. JAMA 2005; 294: 2996-3002.

14 MacDonald AA, Herbison GP, Showell M, Farquhar CM. The impact of body mass index on semen parameters and reproductive hormones in human males: a systematic review with meta-analysis. Hum Reprod Update 2010; 16: 293-311.

15 Ramlau-Hansen $\mathrm{CH}$, Hansen M, Jensen CR, Olsen J, Bonde JP et al. Semen quality and reproductive hormones according to birth weight and body mass index in childhood and adult life: two decades of follow-up. Fertil Steril 2010; 94: 610-8.

16 Rohrmann S, Shiels MS, Lopez DS, Rifai N, Nelson WG et al. Body fatness and sex steroid hormone concentrations in US men: results from NHANES III. Cancer Causes Control 2011; 22: 1141-51. 
17 Cabler S, Agarwal A, Flint M, du Plessis SS. Obesity: modern man's fertility nemesis. Asian J Androl 2010; 12: 480-9.

18 Hakonsen LB, Thulstrup AM, Aggerholm AS, Olsen J, Bonde JP et al. Does weight loss improve semen quality and reproductive hormones? Results from a cohort of severely obese men. Reprod Health 2011; 8: 24.

19 Khoo J, Piantadosi, C, Worthley S, Wittert GA. Effects of low-energy diet on sexua function and lower urinary tract symptoms in obese men. Int J Obes (Lond) 2010; 34 1396-403.

20 Govonlu S, Wooding FG. Pharmacological management of benign prostatic hypertrophy with phosphodiesterase-5 inhibitors. Consult Pharm 2009; 24: 769-71.

21 Khoo J, Piantadosi C, Duncan R, Worthley SG, Jenkins A et al. Comparing effects of low-energy diet and a high-protein low-fat diet on sexual and endothelial function, urinary tract symptoms, and inflammation in obese diabetic men. J Sex Med 2011; 8 2868-75.

22 Reis LO, Favaro WJ, Barreiro GC, de Oliveira LC, Chaim EA et al. Erectile dysfunction and hormonal imbalance in morbidly obese male is reversed after gastric bypass surgery: a prospective randomized controlled trial. Int J Androl 2010; 33: 736-44.

23 Dallal RM, Chernoff A, O'Leary MP, Smith JA, Braverman JD et al. Sexual function is common in the morbidly obese male and improves after gastric bypass surgery. $J A m$ Coll Surg 2008; 207: 859-65.

24 Schroeder R, Garrison JM Jr, Johnson MS. Treatment of adult obesity with bariatric surgery. Am Fam Physician 2011; 84: 805-14.

25 Rao SR, Kini S, Tamler R. Sex hormones and bariatric surgery in men. Gend Med 2011; 8: 300-11.

26 Hammoud A, Gibson M, Hunt SC, Adams TD, Carrell DT et al. Effect of Roux-en-Y gastric bypass surgery on the sex steroids and quality of life in obese men. J Clin Endocrinol Metab 2009; 94: 1329-32.

27 Ranasinghe WK, Wright T, Attia J, McElduff P, Doyle T et al. Effects of bariatric surgery on urinary and sexual function. BJU Int 2011; 107: 88-94.

28 Kaukua J, Pekkarinen T, Sane T, Mustajoki P. Sex hormones and sexual function in obese men losing weight. Obes Res 2003; 11: 689-94.

29 Kaukua J, Pekkarinen T, Sane T, Mustajoki P. Health-related quality of life in obese outpatients losing weight with very-low-energy diet and behaviour modification-2-y follow-up study. Int J Obes Relat Metab Disord 2003; 27: 1233-41.

30 Cheng JY, Ng EM, Ko JS, Chen RY. Physical activity and erectile dysfunction: metaanalysis of population-based studies. Int J Impot Res 2007; 19: 245-52.

31 Hsiao W, Shrewsberry AB, Moses KA, Johnson TV, Cai AW et al. Exercise is associated with better erectile function in men under 40 as evaluated by the International Index of Erectile Dysfunction. J Sex Med 2012; 9: 524-30.

32 Feldman HA, Johannes CB, Derby CA, Kleinman KP, Mohr BA et al. Erectile dysfunction and coronary risk factors: prospective results from the Massachusetts Male Aging Study. Prev Med 2000; 30: 328-38.

33 Bacon CG, Mittleman MA, Kawachi I, Giovannucci E, Glasser DB et al. A prospective study of risk factors for erectile dysfunction. J Urol 2006; 176: 217-21.

34 Ponholzer A, Temmi C, Mock K, Marszalek M, Obermayr R et al. Prevalence and risk factors for erectile dysfunction in 2869 men using a validated questionnaire. Eur Urol 2005; 47: 80-5.

35 Rosen RC, Wing RR, Schneider S, Wadden TA, Foster GD et al. Erectile dysfunction in type 2 diabetic men: relationship to exercise fitness and cardiovascular risk factors in the Look AHEAD trial. J Sex Med 2009; 6: 1414-22.

36 Lamina S, Okoye CG, Dagogo TT. Therapeutic effect of an interval exercise training program in the management of erectile dysfunction in hypertensive patients. J Clin Hypertens (Greenwich) 2009; 11: 125-9.

37 Cheng JY, Ng EM. Body mass index, physical activity and erectile dysfunction: an Ushaped relationship from population-based study. Int J Obes 2007; 31: 1571-8.

38 Janiszewski PM, Janssen I, Ross R. Abdominal obesity and physical inactivity are associated with erectile dysfunction independent of body mass index. J Sex Med 2009; 6: 1990-8.

39 Kratzik CW, Lackner JE, Mark I, Rucklinger E, Schmidbauer J et al. How much physical activity is needed to maintain erectile function? Results of the Androx Vienna Municipality Study. Eur Urol 2009; 55: 509-16.

40 Pohjantahti-Maaroos H, Palomaki A, Hartikainen J. Erectile dysfunction, physical activity and metabolic syndrome: differences in markers of atherosclerosis. $B M C$ Cardiovasc Disord 2011; 22: 36

41 Maio G, Saraeb S, Marchiori A. Physical function and PDE5 inhibitors in the treatment of erectile dysfunction: results of a randomized controlled study. J Sex Med 2010; 7: 2201-8.

42 Moyad MA. Dr. Moyad's Guide to Male Sexual Health. Ann Arbor, MI: Spry Publishing 2012.

43 Claudino MA, Delbin MA, Franco-Penteado CF, Priviero FB, de Nucci G et al. Exercise training ameliorates the impairment of endothelial and nitrergic corpus cavernosum responses in diabetic rats. Life Sci $2011 ; 88$ : 272-7.

44 Claudino MA, Franco-Penteado CF, Priviero FB, Camargo EA, Teixeira SA et al. Upregulation of gp91phox subunit of $N A D(P) H$ oxidase contributes to erectile dysfunction caused by long-term nitric oxide inhibition in rats: Reversion by regular physical training. Urology 2010; 75: 961-7.

45 Zheng H, Mayhan WG, Patel KP. Exercise training improves the defective centrally mediated erectile responses in rats with type I diabetes. J Sex Med 2011; 8: 308697.

46 Dogru MT, Basar MM, Haciislamoglu A. The difference in heart rate recovery between males with and without erectile dysfunction. Ann Noninvasive Electrocardiol 2010, 15: 223-9.
47 Lee JY, Joo KL, Kim JT, Cho ST, Cho DS et al. Heart rate variability in men with erectile dysfunction. Int Neurourol 2011; 15: 87-91.

48 Nauman J, Janszky I, Vatten LJ, Wisloff U. Temporal changes in resting heart rate and deaths from ischemic heart disease. JAMA 2011; 306: 2579-87.

49 Pohjantahti-Maaroos H, Palomaki A. Comparison of metabolic syndrome subjects with and without erectile dysfunction-levels of circulating oxidized LDL and arterial elasticity. Int J Clin Pract 2011; 65: 274-80.

50 Tan HM, Tong SF, Ho CC. Men's health: sexual dysfunction, physical, and psychological health-is there a link? J Sex Med 2012; 9: 663-71.

51 Montejo A, Liorca G, Izquierdo J, Rico-Villademoros F. Incidence of sexual dysfunction associated with antidepressant agents: a prospective multicenter study of 1022 outpatients. Spanish Working Group for the study of psychotropic-related sexual dysfunction. J Clin Psychiatry 2001; 62 (Suppl 3): 10-21.

52 Nahas R, Sheikh 0 . Complementary and alternative medicine for the treatment of major depressive disorder. Can Fam Physician 2011; 57: 659-63.

53 Mead GE, Morley W, Campbell P, Greig CA, McMurdo M et al. Exercise for depression. Cochrane Database Syst Rev 2009; (3): CD004366.

54 Krogh J, Nordentoft M, Sterne JA, Lawlor DA. The effect of exercise in clinically depressed adults: systematic review and meta-analysis of randomized controlled trials. J Clin Psychiatry 2011; 72: 529-38.

55 Melnik T, Soares BG, Nasselo AG. Psychological interventions for erectile dyfunction Cochrane Database Syst Rev 2007; (3): CD004825.

56 Londono DC, Slezak JM, Quinn VP, van den Eeden SK, Loo RK et al. Population-based study of erectile dysfunction and polypharmacy. BJU Int 2012; 110: 254-9.

57 Serretti A, Chiesa A. Sexual side effects of pharmacological treatment of psychiatric diseases. Clin Pharmacol Ther 2011; 89: 142-7.

58 Traish AM, Hassani J, Guay AT, Zitzmann M, Hansen ML. Adverse side effects of 5alpha-reductase inhibitors therapy: persistent diminished libido and erectile dysfunction and depression in a subset of patients. J Sex Med 2011; 8: 872-84.

59 Gleason JM, Slezak JM, Jung H, Reynolds K, van den Eeden SK et al. Regular nonsteroidal anti-inflammatory drug use and erectile dysfunction. J Urol 2011 185: 1388-93.

60 Tengs TO, Osgood ND. The link between smoking and impotence: two decades of evidence. Prev Med 2001; 32: 447-52.

61 Polsky JY, Aronson KJ, Heaton JP, Adams MA. Smoking and other lifestyle factors in relation to erectile dysfunction. BJU Int 2005; 96: 1355-9.

62 Kupelian V, Link CL, McKinlay JB. Association between smoking, passive smoking, and erectile dysfunction: results from the Boston Area Community Health (BACH) Survey. Eur Urol 2007; 52: 416-22.

$63 \mathrm{He} \mathrm{J}$, Reynolds K, Chen J, Chen CS, Wu X et al. Cigarette smoking and erectile dysfunction among Chinese men without clinical vascular disease. Am J Epidemio 2007; 166: 803-9.

64 Ferlay J, Shin HR, Bray F, Forman D, Mathers C et al. GLOBOCAN 2008, Cance Incidence and Mortality Worldwide, IARC CancerBase No. 10. Lyon: International Agency for Research on Cancer; 2010. Available from: http://globocan.iarc.fr.

65 Laniado-Laborin R. Smoking cessation intervention: an evidence-based approach. Postgrad Med 2010; 122: 74-82.

66 Christensen BS, Gronbaek M, Pedersen BV, Graugaard C, Frisch M. Associations of unhealthy lifestyle factors with sex inactivity and sexual dysfunctions in Denmark. J Sex Med 2011; 8: 1903-16.

67 Lee AC, Ho LM, Yip AW, Fan S, Lam TH. The effect of alcohol drinking on erectile dysfunction in Chinese men. Int J Impot Res 2010; 22: 272-8.

68 Cheng JY, Ng EM, Chen RY, Ko JS. Alcohol consumption and erectile dysfunction: meta-analysis of population-based studies. Int J Impot Res 2007; 19: 343-52.

69 Chew KK, Bremner A, Stuckey B, Earle C, Jamrozik K. Alcohol consumption and male erectile dysfunction: an unfounded reputation for risk. J Sex Med 2009; 6: 1386-94.

70 Axelsson J, Ingre M, Akerstedt T, Holmback U. Effects of acutely displaced sleep on testosterone. J Clin Endocrinol Metab 2005; 90: 4530-5.

71 Luboshitzky R, Shen-Orr Z, Herer P. Middle-aged men secrete less testosterone at night than young healthy men. J Clin Endocrinol Metab 2003; 88: 3160-6.

72 Andersen ML, Tufik S. The effects of testosterone on sleep and sleep-disordered breathing in men: its bidirectional interaction with erectile function. Sleep Med Rev 2008; 12: 365-79.

73 Leproult $\mathrm{R}$, van Cauter E. Effect of 1 week of sleep restriction on testosterone levels in young healthy men. JAMA 2011; 305: 2174-5.

74 Esposito K, Giugliano F, di Palo C, Giugliano G, Marfella R et al. Effect of lifestyle changes on erectile dysfunction in obese men: a randomized controlled trial. JAMA 2004; 291: 2978-84.

75 Esposito K, Marfella R, Ciotola M, di Palo C, Giugliano F et al. Effect of a Mediterranean-style diet on endothelial dysfunction and markers of vascular inflammation in the metabolic syndrome: a randomized trial. JAMA 2004; 292: 1440-6.

76 Gulec S. The JUPITER trial: a new approach in primary prevention. Turk Kardiyol Drn Ard 2009; 37 (Suppl 4): 18-26.

77 Yamashita S, Kato R, Kobayashi K, Hisasue S, Arai Y et al. Inhibition of interleukin-6 attenuates erectile dysfunction in a rat model of nerve-sparing radical prostatectomy. J Sex Med 2011; 8: 1957-64.

78 Esposito K, Ciotola M, Giugliano F, Maiorino MI, Autorino R et al. Effects of intensive lifestyle changes on erectile dysfunction in men. J Sex Med 2009; 6: 243-50.

79 Wing RR, Rosen RC, Fava JL, Bahnson J, Brancati F et al. Effects of weight loss intervention on erectile function in older men with type 2 diabetes in the Look AHEAD trial. J Sex Med 2010; 7: 156-65. 
80 Kolotkin RK, Binks M, Crosby RD, Ostbyte T, Mitchell JE et al. Improvements in sexual quality of life after moderate weight loss. Int J Impot Res 2008; 20: 487-92.

81 Pinnock CB, Stapleton AM, Marshall VR. Erectile dysfunction in the community: a prevalence study. Med J Aust 1999; 171: 353-7.

82 Madersbacher S, Temml C, Racz U, Mock K, Ponholzer A et al. Prevalence and risk factors for erectile dysfunction in Austria-analysis of a health screening project. Wien Klin Wochenschr 2003; 115: 822-30.

83 Nicolosi A, Glasser DB, Moreira ED, Villa M; for the Erectile Dysfunction Epidemiology Cross National Study Group. Prevalence of erectile dysfunction and associated factors among men without concomitant diseases: a population study. Int J Impot Res 2003; 15: 253-7.

84 Bhojani N, Perrotte P, Hutterer G, Suardi N, Jeldres C et al. Body mass index and its association with genitourinary disorders in men undergoing prostate cancer screening. J Sex Med 2008; 5: 2141-51.

85 Elbendary MA, El-Gamal OM, Salem KA. Analysis of risk factors for erectile dysfunction in Egyptian patients under the age of 40 years. J Androl 2009; 30: $520-4$

86 Shiri R, Koskimaki J, Hakama M, Hakkinen J, Huhtala $\mathrm{H}$ et al. Effect of life-style factors on incidence of erectile dysfunction. Int J Impot Res 2004; 16: 389-94.

87 Bajos N, Wellings K, Laborde C, Moreau C; CSF Group. Sexuality and obesity, a gender perspective: results from French national random probability survey of sexual behaviors. BMJ 2010; 340: c2573.

88 Nikoobakht M, Pourkasmaee M, Nasseh $\mathrm{H}$. The relationship between lipid profile and erectile dysfunction. Urol J 2005; 2: 40-4.

89 Heruti R, Shochat T, Tekes-Manova D, Askenazi I, Justo D. Association between erectile dysfunction and sleep disorders measured by self-assessment questionnaires in adult men. J Sex Med 2005; 2: 543-50.

90 Ghalayini IF, Al-Ghazo MA, Al-Azab R, Bani-Hani I, Matani YS et al. Erectile dysfunction in a Mediterranean country: results of an epidemiological survey of a representative sample of men. Int J Impot Res 2010; 22: 196-203.

91 Ahn TY, Park JK, Lee SW, Hong JH, Park NC et al. Prevalence and risk factors for erectile dysfunction in Korean men: results of an epidemiological study. J Sex Med 2007; 4: 1269-76.

92 Hernandez Moreno PN, Mendoza Martinez R, Hernandez Marin I, Tovar Rodriguez JM, Ayala AR. Epidemiologic assessment of erectile function in a selected Mexican population. Ginecol Obstet Mex 2003; 71: 332-42.

93 Teles AG, Carreira M, Alarcao V, Sociol D, Aragues JM et al. Prevalence, severity, and risk factors for erectile dysfunction in a representative sample of 3,548 portuguese men aged 40 to 69 years attending primary healthcare centers: results of the Portuguese erectile dysfunction study. J Sex Med 2008; 5: 1317-24.

94 Bener A, Al-Ansari A, Al-Hamaq AO, Elbagi IE, Afifi M. Prevalence of erectile dysfunction among hypertensive and nonhypertensive Qatari men. Medicina (Kaunas) 2007; 43: 870-8.

95 Al Helali NS, Abolfotouh MA, Ghanem HM. Pattern of erectile dysfunction in Jeddah city. Saudi Med J 2001; 22: 34-8.

96 Tan JK, Hong CY, Png DJ, Liew LC, Wong ML. Erectile dysfunction in Singapore: prevalence and its associated factors-a population-based study. Singapore Med J 2003; 44: 20-6.

97 Kongkanand A. Prevalence of erectile dysfunction in Thailand. Thai Erectile Dysfunction Epidemiological Study Group. Int J Androl 2000; 23 (Suppl 2): 77-80.

98 Derby CA, Mohr BA, Goldstein I, Feldman HA, Johannes CB et al. Modifiable risk factors and erectile dysfunction: can lifestyle changes modify risk? Urology 2000; 56: 302-6.

99 Kostis JB, Jackson G, Rosen R, Barrett-Connor E, Billups K et al. Sexual dysfunction and cardiac risk (the Second Princeton Consensus Conference). Am J Cardiol 2005; 96: 313-21.

100 Montague DK, Jarow JP, Broderick GA, Dmochowski RR, Heaton JP et al. Chapter 1: The management of erectile dysfunction: an AUA update. J Urol 2005; 174: 230-9.

101 Hasegawa T, Saijo M, Ishii T, Nagata T, Haishima Y et al. Structural elucidation of a tadalafil analogue found in a dietary supplement. Shokuhin Eiseigaku Zasshi 2008; 49: 311-5.

102 Venhuis BJ, Zomer G, Hamzink M, Meiring HD, Aubin Y et al. The identification of a nitrosated prodrug of the PDE-5 inhibitor aildenafil in a dietary supplement: a Viagra with a pop. J Pharm Biomed Anal 2011; 54: 735-41.

103 No authors listed. Two dietary supplements contain undeclared ingredient. FDA Consum 2005; 39: 6

104 Choi KT. Botanical characteristics, pharmacological effects and medicinal components of Korean Panax ginseng C A Meyer. Acta Pharmacol Sin 2008; 29: 1109-18.

105 Yue PY, Mak NK, Cheng YK, Leung KW, Ng TB et al. Pharmacogenomics and the Yin/ Yang actions of ginseng: anti-tumor, angiomodulating and steroid-like activities of ginsenosides. Chin Med 2007; 2: 6

106 Lee DC, Lau AS. Effects of Panax ginseng on tumor necrosis factor-alpha-mediated inflammation: a mini-review. Molecules 2011; 16: 2802-16.

107 Chu SF, Zhang JT. New achievements in ginseng research and its future prospects. Chin J Integr Med 2009; 15: 403-8.

108 Kiefer D, Pantuso T. Panax ginseng. Am Fam Physician 2003; 68: 1539-42.

109 Christensen LP. Ginsenosides chemistry, biosynthesis, analysis, and potential health effects. Adv Food Nutr Res 2009; 55: 1-99.

110 Attele AS, Wu JA, Yuan CS. Ginseng pharmacology: multiple constituents and multiple actions. Biochem Pharmacol 1999; 58: 1685-93.
111 Jia L, Zhao Y. Current evaluation of the millennium phytomedicine-ginseng (I): etymology, pharmacognosy, phytochemistry, market and regulations. Curr Med Chem 2009; 16: 2475-84

112 Bucci LR. Selected herbals and human exercise performance. Am J Clin Nutr 2000; 72 (Suppl): 624S-34S.

113 Jovanovski E, Jenkins A, Dias AG, Peeva V, Sievenpiper J et al. Effects of Korean red ginseng (Panax ginseng C.A. Mayer) and its isolated ginsenosides and polysaccharides on arterial stiffness in healthy individuals. Am J Hypertens 2010; 23: 469-72.

114 Khera M, Goldstein I. Erectile Dysfunction. Clin Evid (Online) 2011; 2011. pii: 1803.

115 Ham WS, Kim WT, Lee JS, Ju HJ, Kang SJ et al. Efficacy and safety of red ginseng extract powder in patients with erectile dysfunction: multicenter, randomized, doubleblind, placebo-controlled study. Kor J Urol 2009; 50: 159-64.

116 Ernst E, Posadzki P, Soo Lee M. Complementary and alternative medicine (CAM) for sexual dysfunction and erectile dysfunction in older men and women: an overview of systematic reviews. Maturitas 2011; 70; 37-41.

117 Jang D-J, Soo Lee M, Shin B-C, Lee Y-C, Ernst E. Red ginseng for treating erectile dysfunction: a systematic review. Brit J ClinPharmacol 2008; 66: 444-50.

$118 \mathrm{Kim} \mathrm{H}$, Chen X, Gillis CN. Ginsenosides protect pulmonary vascular endothelium against free radical-induced injury. Biochem Biophys Res Commun 1992; 189: 670-6.

119 Chen X, Lee TJ. Ginsenosides-induced nitric oxide-mediated relaxation of the rabbit corpus cavernosum. Br J Pharacol 1995; 115: 15-8.

120 Chen X. Cardiovascular protection by ginsenosides and their nitric oxide releasing action. Clin Exp Pharmacol Physiol 1996; 23:728-32.

121 Choi YD, Xin ZC, Choi HK. Effect of Korean red ginseng on the rabbit corpus cavernosal smooth muscle. Int J Impot Res 1998; 10: 37-43.

122 Choi YD, Rha KH, Choi HK. In vitro and in vivo experimental effect of Korean red ginseng on erection. J Urol 1999; 162: 1508-11.

123 Wang X, Chu S, Qian T, Chen J, Zhang J. Ginsenoside Rg1 improves male copulatory behavior via nitric oxide/cyclic guanosine monophosphate pathway. J Sex Med 7 (2 Pt 1): 2010; 743-50.

124 Han K, Shin IC, Choi KJ, Yun YP, Hong JT et al. Korea red ginseng water extract increases nitric oxide concentrations in exhaled breath. Nitric Oxide 2005; 12: 159-62.

125 Kimura T, Saunders PA, Kim HS, Rheu HM, Oh KW et al. Interactions of ginsenosides with ligand-bindings of $\mathrm{GABA}(\mathrm{A})$ and $\mathrm{GABA}(\mathrm{B})$ receptors. Gen Pharmacol 1994; 25 : 193-9.

126 Park JH, Cha HY, Seo JJ, Hong JT, Han K et al. Anxiolytic-like effects of ginseng in the elevated plus-maze model: comparison of red ginseng and sun ginseng. Prog Neuropsychopharmacol Biol Psychiatry 2005; 29: 895-900.

127 Watanabe H, Ohta H, Imamura L, Asakura W, Matoba Y et al. Effect of Panax ginseng on age-related changes in the spontaneous motor activity and dopaminergic nervous system in the rat. Jpn J Pharmacol 1991; 55: 51-6.

128 Murphy LL, Cadena RS, Chavez D, Ferraro JS. Effect of American ginseng (Panax quinquefolium) on male copulatory behaviour in the rat. Physiol Behav 1998; 64: 445-50.

129 de Andrade E, de Mesquita AA, Claro Jde A, de Andrade PM, Ortiz V et al. Study of the efficacy of Korean red ginseng in the treatment of erectile dysfunction. Asian J Androl 2007; 9: 241-4.

130 Dang H, Chen Y, Liu X, Wang Q, Wang L et al. Antidepressant effects of ginseng total saponins in the forced swimming test and chronic mild stress models of depression. Prog Neuropsychopharmacol Biol Psychiatry 2009; 33: 1417-24.

131 Lee B, Kim H, Shim I, Lee H, Hahm DH. Wild ginseng attenuates anxiety- and depression-like behaviors during morphine withdrawal. J Microbiol Biotechnol 2011; 21: 1088-96.

132 Buettner C, Yeh GY, Phillips RS, Mittleman MA, Kaptchuk TJ. Systematic review of the effects of ginseng on cardiovascular risk factors. Ann Pharmacother 2006; 40: 83-

133 Karmazyn M, Moey M, Gan XT. Therapeutic potential of ginseng in the management of cardiovascular disorders. Drugs 2011; 71: 1989-2008.

$134 \mathrm{Kim}$ SY, Seo SK, Choi YM, Jeon YE, Lim KJ et al. Effects of red ginseng supplementation on menopausal symptoms and cardiovascular risk factors in posmenopausal women: a double-blind randomized controlled trial. Menopause 2012; 19: 461-6.

135 Barton DL, Soori GS, Bauer BA, Sloan JA, Johnson PA et al. Pilot study of Panax quinquefolius (American ginseng) to improve cancer-related fatigue: a randomized, double-blind, dose-finding evaluation: NCCTG trial N03CA. Support Care Cancer 2010; 18: 179-87.

136 Tode T, Kikuchi Y, Hirata J, Kita T, Nakata $\mathrm{H}$ et al. Effect of Korean red ginseng on psychological functions in patients with severe climacteric syndromes. Int J Gynaecol Obstet 1999; 67: 169-74.

137 Reay JL, Kennedy DO, Scholey AB. Effects of Panax ginseng, consumed with and without glucose, on blood glucose levels and cognitve performance during sustained "mentally demanding" tasks. J Psychopharmacol 2006; 20: 771-81.

138 Rausch WD, Liu S, Gille G, Radad K. Neuroprotective effects of ginsenosides. Acta Neurobiol Exp (Wars) 2006; 66: 369-75.

$139 \mathrm{Ma}$ J, Li W, Tian R, Lei W. Ginsenoside Rg1 promotes peripheral nerve generation in rat model of nerve crush injury. Neurosci Lett 2010; 478: 66-71.

140 Zheng GQ, Cheng W, Wang Y, Wang XM, Zhao SZ et al. Ginseng total saponins enhance neurogenesis after focal cerebral ischemia. J Ethnopharmacol 2011; 133: 724-8.

141 Fang F, Chen X, Huang T, Lue LF, Luddy JS et al. Multi-faced neuroprotective effects of ginsenoside Rg1 in an Alzheimer mouse model. Biochim Biophys Acta 2012; 1822: 286-92. 
142 Liang W, Ge S, Yang L, Yang M, Ye Z et al. Ginsenosides Rb1 and Rg1 promote proliferation and expression of neurotrophic factors in primary Schwann cell cultures. Brain Res 2010; 1357: 19-25.

143 Lopez MV, Cuadrado MP, Ruiz-Poveda OM, del Fresno AM, Accame ME. Neuroprotective effect of individual ginsenosides on astrocytes primary culture. Biochim Biophys Acta 2007; 1770: 1308-16.

144 Lee ST, Chu K, Sim JY, Heo JH, Kim M. Panax ginseng enhances cognitive performance in Alzheimer disease. Alzheimer Dis Assoc Disord 2008; 22: 222-6.

$145 \mathrm{Heo} \mathrm{JH}$, Lee ST, Chu K, Oh MJ, Park HJ et al. An open-label trial of Korean red ginseng as an adjuvant treatment for cognitive impairment in patients with Alzheimer's disease. Eur J Neurol 2008; 15: 865-8.

146 Geng J, Dong J, Ni H, Lee MS, Wu T et al. Ginseng for cognition. Cochrane Database Syst Rev 2010; (12): CD007769.

147 Colman $\mathrm{Cl}$, Hebert JH, Reddy P. The effects of Panax ginseng on quality of life. J Clin Pharm Ther 2003; 28: 5-15.

148 http://www.fda.gov (accessed 9 February 2012).

149 ChromaDex®, Boulder, CO, USA. http://www.chromadex.com (accessed 28 September 2010)

150 Chan PC, Peckham JC, Malarkey DE, Kissling GE, Travlos GS et al. Two-year toxicity and carcinogenicity studies of Panax ginseng in Fischer 344 rats and B6C3F1 mice. Am J Chin Med 2011; 39: 779-88.

151 National Toxicology Program. Toxicology and carcinogenesis studies of ginseng (CAS No.50647-08-0) in F344/N rats and B6C3F1 mice (gavage Studies). Natl Toxicol Program Tech Rep Ser 2011; 567: 1-149.

152 Coon JT, Ernst E. Panax ginseng: a systematic review of adverse effects and drug interactions. Drug Saf 2002; 25: 323-44.

153 Izzo AA, Ernst E. Interactions between herbal medicines and prescribed drugs. An updated systematic review. Drugs 2009; 69: 1777-98.

154 Siegel RK. Ginseng abuse syndrome. Problems with the panacea. JAMA 1979; 241 1614-5.

155 Baldwin CA, Anderson LA, Phillipson JA. What pharmacists should know about ginseng. Pharm J 1986; 237: 583-6.

156 Miller LG. Herbal medicinals: Selected clinical considerations focusing on known or potential drug-herb interactions. Arch Intern Med 1998; 158: 2200-11.

157 Klepser TB, Klepser ME. Unsafe and potentially safe herbal therapies. Am J Health Syst Pharm 1999; 56: 125-41.

158 Stavro PM, Woo M, Heim TF, Leiter LA, Vuksan V. North American ginseng exerts a neutral effect on blood pressure in individuals with hypertension. Hypertension 2005 46: 406-11.

159 Stavro PM, Woo M, Leiter LA, Heim TF, Sievenpiper JL et al. Long-term intake of North American ginseng has no effect on 24-hour blood pressure and renal function. Hypertension 2006; 47: 791-6.

160 Caron MF, Hotsko AL, Robertson S, Mandybur L, Kluger J et al. Electrocardiographic and hemodynamic effects of panax ginseng. Ann Pharmacother 2002; 36: 758-63.

$161 \mathrm{Han}$ JH, Choe SC, Kim HS, Sohn DW, Nam KY et al. Effect of red ginseng on blood pressure in patients with essential hypertension and white coat hypertension. $\mathrm{Am} \mathrm{J}$ Chin Med 1998; 26: 199-209.

162 Rhee MY, Kim YS, Bae JH, Nah DY, Kim YK et al. Effect of Korean ginseng on arterial stiffness in subjects with hypertension. J Altern Complement Med 2011; 17: 45-9.

163 Vuksan V, Sung MK, Sievenpiper JL, Stavro PM, Jenkins AL et al. Korean red ginseng (Panax ginseng) improves glucose and insulin regulation in well-controlled, type 2 diabetes: results of a randomized, double-blind, placebo-controlled study of efficacy and safety. Nutr Metab Cardiovasc Dis 2008; 18: 46-56.

164 Ang-Lee MK, Moss J, Yuan CS. Herbal medicines and perioperative care. JAMA 2001; 286: $208-16$

165 Jiang X, Williams KM, Liauw WS, Ammit AJ, Roufogalis BD et al. Effect of St John's wort and ginseng on the pharmacokinetics and pharmacodynamics of warfarin in healthy subjects. Br J Clin Pharmacol 2004; 57: 592-9.

166 Jiang X, Williams KM, Liauw WS, Ammit AJ, Roufogal is BD et al. Effect of ginkgo and ginger on the pharmacokinetics and pharmacodynamics of warfarin in healthy subjects. Br J Clin Pharmacol 2005; 59: 425-32.

167 Jiang X, Blair EY, McLachlan AJ. Investigation of the effects of herbal medicines on warfarin response in healthy subjects: a population pharmacokineticpharmacodynamic modeling approach. J Clin Pharmacol 2006; 46: 1370-8.
168 Lee YH, Lee BK, Choi YJ, Yoon IK, Chang BC et al. Interaction between warfarin and Korean red ginseng in patients with cardiac valve replacement. Int J Cardiol 2010; 145: 275-6.

169 Lee S-H, Ahn Y-M, Ahn S-Y, Doo H-K, Lee B-C. Interaction between warfarin and Panax ginseng in ischemic stroke patients. J Alt Comp Med 2008; 14: 715-21.

170 Yuan CS, Wei G, Dey L, Karrison T, Nahlik L et al. Brief communication: American ginseng reduces warfarin's effect in healthy patients: a randomized, controlled trial. Ann Intern Med 2004; 141: 23-7.

171 Yu JY, Jin YR, Lee JJ, Chung JH, Noh JY et al. Antiplatelet and antithrombotic activities of Korean red ginseng. Arch Pharm Res 2006; 29: 898-903.

172 Vaes LP, Chyka PA. Interactions of warfarin with garlic, ginger, ginkgo, or ginseng: nature of the evidence. Ann Pharmacother 2000; 34: 1478-82.

173 Bahrke MS, Morgan WP. Evaluation of the ergogenic properties of ginseng. Sports Med 1994; 18: 229-48.

174 Chuang WC, Wu HK, Sheu SJ, Chiou SH, Chang HC et al. A comparative study on commercial samples of ginseng radix. Planta Med 1995; 61: 459-65.

175 Kim T-H, Jeon SH, Hahn E-J, Paek K-Y, Park JK et al. Effects of tissue-cultured mountain ginseng (Panax ginseng CA Meyer) extract on male patients with erectile dysfunction. Asian J Androl 2009; 11: 356-61.

176 Kim HS, Woo SH, Jo S, Hahn E-J, Youn NY et al. Double-blind, placebo-controlled, multi-center study for therapeutic effects of Mountain Panax Ginseng C.A. Meyer extract in men with erectile dysfunction: a preliminary report. Korean J Androl 2006; 24: 84-8.

177 Vohra S, Johnston BC, Laycock KL, Midodzi WK, Dhunnoo I et al. Safety and tolerability of North American ginseng extract in the treatment of pediatric upper respiratory tract infection: a phase II randomized, controlled trial of 2 dosing schedules. Pediatrics 2008; 122: e402-10.

$178 \mathrm{Ha} \mathrm{KC}$, Kim MG, Oh MR, Choi EK, Back HI et al. A placebo-controlled trial of Korean red ginseng extract for preventing influenza-like illness in healthy adults. $B M C$ Complement Altern Med 2012; 12: 10

179 Seida JK, Durec T, Kuhle S. North American (Panax quinquefolius) and Asian ginseng (Panax ginseng) preparations for prevention of the common cold in healthy adults: systematic review. Evid Based Complement Alternat Med 2011; 2011: 282151.

180 Ledda A, Belcaro G, Cesarone MR, Dugall M, Schonlau F. Investigation of a complex plant extract for mild to moderate erectile dysfunction in a randomized, double-blind, placebo-controlled, parallel-arm study. BJU Int 2010; 106: 1030-3.

181 Shin BC, Lee MS, Yang EJ, Lim HS, Ernst E. Maca (L. meyenii) for improving sexual function: a systematic review. BMC Complement Altern Med 2010; 10: 44

182 Cormio L, de Siati M, Lorusso F, Selvaggio O, Mirabella L et al. Oral L-citrulline supplementation improves erection hardness in men with mild erectile dysfunction. Urology 2011; 77: 119-22.

183 Cavallini G, Caracciolo S, Vitali G, Modenini F, Biagiotti G. Carnitine versus androgen administration in the treatment of sexual dysfunction, depressed mood, and fatigue associated with male aging. Urology 2004; 63: 641-6.

184 Gentile V, Antonini G, Antonella Bertozzi M, Dinelli N, Rizzo C et al. Effect of propionyl-L-carnitine, L-arginine and nicotinic acid on the efficacy of vardenafil in the treatment of erectile dysfunction in diabetes. Curr Med Res Opin 2009; 25 2223-8.

185 Gianfrilli D, Lauretta R, di Dato C, Graziadio C, Pozza C et al. Propionyl-L-carnitine, Larginine and niacin in sexual medicine: a nutraceutical approach for erectile dysfunction. Andrologia 2012; 44 (Suppl 1): 600-4.

186 Kim S-O, Kim MK, Lee H-S, Park JK, Park K. The effect of Korean red ginseng extract on the relaxation response in isolated rabbit vaginal tissue and its mechanism. J Sex Med 2008; 5: 2079-84.

187 Lee H-S, Lee MN, Hwang IS, Kim SO, Ahn K et al. Effect of Korean red ginseng on vaginal blood flow and structure in hypercholesterolemic female rats. Korean J Androl 2005; 23: 159-64.

$188 \mathrm{Kim}$ S-O, Kim MK, Chae MJ, Kim HY, Park JK et al. Effect of Korean red ginseng on the relaxation of clitoral corpus cavernosum in rabbit. Korean J Androl 2006; 24: 29-34.

189 Oh K-J, Chae M-J, Lee H-S, Hong H-D, Park K. Effects of Korean red ginseng on sexua arousal in menopausal women: placebo-controlled, double-blind crossover clinical study. J Sex Med 2010; 7: 1469-77.

190 Price A, Gazewood J. Korean red ginseng effective for treatment of erectile dysfunction. J Fam Pract 2003; 52: 20-1.

191 Tal R, Teloken P, Mulhall JP. Erectile function after radical prostatectomy: practice patterns among AUA members. J Sex Med 2011; 8: 2370-6. 